\title{
How to Deal with Differing Views of Resource Efficiency when Carrying Out Digitalization Projects
}

\author{
Sten GRAHN ${ }^{\mathrm{a} 1}$, Anna GRANLUND ${ }^{\mathrm{b}}$ and Erik LINDHULT $^{\mathrm{b}}$ \\ ${ }^{a}$ Rise IVF AB, Sweden \\ ${ }^{\mathrm{b}}$ Mälardalen University, Sweden
}

\begin{abstract}
Having project goals that are shared among project members are preconditions for resource efficient as well effective projects and operations. However, specifying and communicating project goals require an ability to identify goals that are indeed commonly shared. Rapid technological developments may require digitalization projects that lead to large portions of existing company staff being redundant, making it possible to assume that the quest of finding a commonly shared view of what is 'resource-efficient' will be increasingly challenging. Development of methods to specify project goals that are incentivizing for all project members and staff can hence be assumed to be important. One step in developing improved specification methods is to ask how the process to specify desired value from digitalization projects handles possible disagreements of what is 'desired value'. The purpose of this study was to answer this question. We analyzed several digitalization projects, and how specifications of desired project results impacted project outcomes. We found that potential disagreements regarding desirable project outcomes generally are avoided by avoiding specification of what a desirable resource efficiency outcome is, and how actual project outcomes should be measured. However, we also found that this practice also led to unsatisfying project outcomes regarding resource-efficiency improvements, and that improved methods to specify desired value from digitalization projects should be developed. Our findings support earlier findings that the general failure rate of digitalization projects is high, often due to insufficient specification of desired projects outcomes before the projects are initiated. Our findings contribute to the understanding that despite this, there are also perceived benefits of spending limited resources on specification of desired outcomes. If attempts to improve the success rate of digitalization projects by improving specifications of desired project outcomes is to succeed, these perceived benefits must be considered.
\end{abstract}

Keywords. Value, resource-efficiency, effectiveness, automation, digitalization

\section{Introduction}

Increasing competition, environmental challenges and market changes make it ever more important for companies to ensure that they utilize their resources as efficient and effective as possible. Rapid technological development is also increasing the technological opportunities to streamline businesses and take full advantage of all existing opportunities to create more value, reduce resource consumption and increase competetiveness. Efficiency, optimization and automation projects can hence be said to be ever more important industrial objectives. A precondition for successful efficiency

\footnotetext{
${ }^{1}$ Corresponding Author. sten.grahn@mdh.se
} 
generating activities is the existence of project goals that are easy to understand and are shared among company staff and project members. From this follows that specifying and communicating these goals within companies should be important. However, specifying and communicating project goals as a means to generate desirable project results is dependent on the ability to identify goals that are indeed commonly shared and incentivizing for project actors. Rapid technological and market developments make it possible to assume that the quest of finding commonly shared project goals and a commonly shared view of what is 'resource efficient' will be increasingly challenging though, as these developments may make it possible, as well as necessary, to carry out automation and digitalization projects that potentially could make significant parts of project members and other company staff redundant, as indicated by e.g. Brynjolfsson and McAfee [1] and Rifkin [2], [3] or lead to organizational changes or require new skills that are demanding for the staff. Improved methods for project goal specification, that are incentivizing for all project members within companies, that support desirable coordination of project resources when automation and other digitalization projects are carried out can hence be assumed to be important to develop. One step in developing improved goal specification methods is to ask how the process to specify desired value from digitalization projects handling possible disagreements of what is 'desired value'. The aim of this study was to answer this question, with the purpose of contributing to methods to improve the success rate of digitalization projects, which current has been deemed "alarmingly" low $^{2}$. The overarching pupose was also to contribute to the Servitization and value research by making a study which takes the value recipient perpective. This literature mainly take the supplier perspective, where e.g. one Servitization literature review 2014 [4] and a more recent one 2019 [5] barely mention the recipient perspective.

SME:s report that the potential benefits of digitalization mainly has been framed towards larger firms [6] and we have therefore focused on SME:s when we analyzed results from several automation and digitalization projects, and how specifications of desired project results have impacted the actual outcome. We found that specification of desirable long-term resource effective outcomes from digitalization projects generally were avoided, which meant that potential disagreements regarding how this increased effectiveness should be achieved, also was avoided. However, we also found that the 'resource efficient' practice of avoiding specifying desired long-term resource effectiveness results led to project outcomes that often could be viewed as unsatisfying, regarding actual long-term resource effectiveness. Our findings contribute to the understanding of how automation and digitalization project initiation and execution could be improved, and as a consequence, making a contribution to fulfilling our overarching purpose of improving future digitalization and automation project outcomes.

\section{Theoretical framework and assumptions}

$\mathrm{Ng}$ and Smith [7] categorize existing value literature into six themes of value understanding: utility, economic worth, perceived satisfaction, net benefit, means end and phenomenological experience. In this work we focus on value as 'economic worth' and assume that an important reason for industry digitalization is a desire to improve economic performance.

\footnotetext{
2 https://www.information-age.com/projects-continue-fail-alarming-rate-123470803/ [accessed 2019-11-06]
} 
We assume that digitalization projects may create several different benefits, having an 'economic worth'. Either by creating values that make it interesting for customers to pay more, or by reducing the need for resources, and costs, required for the value creation. We therefore assume that desired value should be viewed as a vector containing several value 'terms' such as V(production capacity/h, product usefulness, lead-time, etc), We also assume that identified resource requirements to install, operate and maintain digital installations as means to create Value $(V)$ should be viewed as a vector of several Resource 'terms' $(R)$ such $R$ (hours, machinery, maintenance/upgrade resources, open access resources, etc). When companies make specifications we assume it relevant to observe how they treat desired $V$ creation and desired $R$ reduction, and how different terms were weighted.

Performance Economy [8] introduces the concept time factor, stressing the importance to recognize that 'performance' should be specified over a chosen time frame, i.e. how created $V$ and reduced $R$ consumption should develop over a relevant time-frame. It has also been said that "The ability to learn faster than your competitors may be the only sustainable competitive advantage." [9]. We hence assume that a crucial outcome for any industrial measure should be to secure as large an increase of the fraction Value/Resources $(V / R)$ over time, as possible. This indicate that industrial projects should secure both optimizability of tools, machinery and production systems, i.e., secure preconditions for optimization, as well as contribute to full utilization of this optimizability. We therefore found it relevant to observe how $V$ and desired reduction of $R$ consumption were specified as to increase $V / R$ over time, including how useful measurements of actual $V$ and $R$ were specified. (From this point on, when we write 'value' we mean ' $V / R$ over time'.)

Accelerating IT development rapidly increase opportunities for companies to be more competitive. However, this same development also makes it ever more challenging for industries to maintain relative competitiveness, as existing competitors can use the same technology to rapidly catch up possible efficiency gaps. We therefore assumed that specification of desired value over time for digitalization projects are particularly important to study. With digitalization projects we mean any project involving software or programmable instructions, for example automation projects or projects involving introductions of digital tools.

Industry can also be said to see a trend from a flow view towards a connected network view of operations. This trend shifts from the view that Value is created in a Value chain mainly within a single company, to something that is co-created [10] by multiple actors in a Value network [11]. This trend we assume will make the issue of Value creation and Resource reduction desired, and created, by whom, increasingly more important when desired value is specified.

In summary, we assumed that the ability to generate successful long-term outcomes from digitalization projects is dependent on five main preconditions; that it is specified how:

- Desired project value is to improve economic performance for the company

- Different value terms should be prioritized and weighted

- Desired value over time, is to be created 
- Diiferent actors should contribute to different types of value

- Actually created value from the projects should be measured

As we studied the process to specify desired value from industrial digitalization projects, we then assumed it would be relevant to reflect on how possible disagreements was handled when the five areas above were considered during the specification process, and we ask the question: How is the process to specify desired value from digitalization projects handling possible disagreements of what is 'desired value'?

\section{Method}

As SME:s play an important part of the network of suppliers to larger enterprises, it is important to decrease the gap in Industry 4.0 implementation between different enterprise categories [12]. With the emerging importance of ecosystems due to Industry 4.0 [13] it is of relevance to build empirical knowledge on the SME:s current practices, in order to guide both future research and to provide managerial implications. We hence focused our interviews and case studies on SME:s and on companies with limited digitalization and value-focused operations experience. We, however, also included interviews with companies with more experience from digitalization projects and valuefocused operations to identify how value specification differ between those company categories, and to get both supplier and recipient perspectives on value specification. The subject of 'desired value' is wide and hard to grasp and to identify relevant questions and get an in depth understanding of how companies specify desired value we used a data gathering process in several steps with data gathering refinements in each step. Value specification experiences from 22 companies in total, assumed sufficient to generate information for generalizability [14] were analyzed.

\subsection{Experiences from an industrial consultant}

An inspiration for the study was experiences that project leaders within an industrial consultancy company have had as an automation project leader from 30 different industrial automation projects between 2004 and 2014, within process and energy industries and mechanical assembly industries. An open-ended question was asked to three consultants: "How are your customers generally specifying desired value from digitalization projects?" The answers from the ensuing discussion were used to generate interview questions, for systematic interviews with other companies.

\subsection{Interviews with SME:s, two suppliers of digital tools and an automation integrator}

Interview results from semi structured interviews [15] with engineers responsible for production development for ten Swedish industrial SME:s regarding how they specify value when making physical automation investments, were used. The majority of the companies reported earlier unsatifying automation outcomes such as "inflexible solutions, costly to upgrade" as reasons for project participation. The data from this group of companies was collected within the LEAD research project when a Lean Automation Handbook for assembly industries was developed [16], with the purpose to guide companies how to apply lean principles for automation projects. Engineers responsible 
for production development for another group of seven SME:s about to increase utilization of digital tools were also interviewed regarding how they specified value from digitalization efforts. 1-3 engineers where interviewed in all companies. This was done within the e-Factory research project.

The interviewees had sometimes different formal titles but were presented by the companies as those 'responsible for production development', including initiation and execution of projects. All digitalization recipient companies could be viewed as taking their first digitalizations steps, or have had unsatisfying experiences from their earlier digitalization projects.

The digitalization recipient interviews above were complemented with interviews with two suppliers of digital tools, and with an experienced automation integrator. These three were also asked the same questions as the SME:s, with the difference that they were asked: "how do you think your customers generally answers the questions regarding how they specify desired value from digitalization projects".

\subsection{In-depth analysis of value specification practices at an international process industry}

A series of six workshops was also held with participants from a midsized international process industry, with the purpose to identify how outcomes of future digitalization projects could be improved, in part by improving the value specification process. These involved the production manager, the manager for the IT-department, project leaders for individual digitalization projects and affiliated automation consultants. The workshop topics were "why is our current project success rate limited?", "how do we specify desired project 'success'?", "how are our organizational and project models supporting 'success' specification?" and "how could our project design be improved?". The project maturity of the company when carrying out digitalization projects could not be viewed as leading edge, which also was a reason for the company's interest in participating in the research project.

\subsection{Analysis and synthesis}

From our empirical study we analyzed the answers, based on the five preconditions mentioned in chapter 1 and clustered the answers accordingly. Regarding the data from the workshops held at the "midsized process industry" we also used the more in-depth information from the workshops to analyze how actual outcomes from earlier projects had differed from specified desired outcomes, to get an indication how insufficient specified desired outcomes could be attributed to unsatisfying actual outcomes, possibly also indicating the reasons for the unsatisfying outcomes from automation projects within the first group of SME:s mentioned above.

\section{Empirical findings}

\subsection{Long term experience from value specification from an industrial consultant}

Responses to our open ended question indicated a generally limited interest in precise specification of desired value from recipients of digitalization projects. Comment from one consultant was e.g. "during all my years I have never come across companies that really considers the questions of desired value. There generally is instead a focus 
on a relatively few project targets, mostly technology specifications. 'Lowered production cost' is often the desired 'value"." And "Limited interest in detailed value specification is also easy to understand as overhearing 'locker room talk' often reveals a wide spread concern about outcomes from digitalization projects, regarding possible job losses and demanding new work requirements." Based on the these experiences, the set of six questions below was produced, to identify how the process to specify desired value avoids possible disagreements, where the 'direct' question: "How is possible disagreements avoided regarding what is 'desired value'?", was left out as it was assumed to be a sensitive question and we rather wanted to analyze how the specification process avoids disagreements.

1, How do you ensure that digitalization projects provide as much value as possible?

2, How is the desired value from digitalization specified?

3, How is actual created value measured?

4, How is the desired value, valued economically?

5 , With which technical method is the desired value ensured?

6, What business model is used to secure the specified value?

\subsection{Interview findings from SME:s, digital tool suppliers and an automation integrator}

The questions in 3.1 were mailed and most of the times the written answers that were mailed back to us from the companies were very short and required follow up phone calls to get deeper insights in the value thinking of the companies. The interviews with the first group of SME:s showed that:

- 'Capacity' and 'improved ergonomics' were the main desired values, and reasons for automation projects

- Reduction of manual hours' and hence assumed reduction of production cost, was the main desired resource reduction. There was awareness that it is not possible to equate reduced manual hours with reduced production cost when making investments, as e.g. the actual savings cannot be captured until freed staff has found other work tasks. However, this awareness did not translate into more precise valuing of the actual impact on production cost for the whole factory over time, as a basis for the investment

- There was a general disinterest in, or experienced difficulty of, formulating other desired value terms and other desired resource reduction, including e.g. a weighted balance of value terms such as reduced 'lead-time' or 'changeover time', 'increased product quality', etc, in combination with increased 'capacity' or 'reduced hours'.

- Different actors within the same company had often different system views, both in space and in time. There was often no common view on how to answer the questions; value for whom? when? during what time-period?

- No answers indicated that an optimizable system was a desired value, and all companies viewed a digital installation very similar to a 'static' installation, e.g. 'a wall', i.e. the issue of how to ensure that the automations projects would ensure possibilities for continuous improvements of their production system was not discussed.

- Actual created value from earlier investments was also rarely evaluated in any detail. "The total impact of investments over time is difficult or impossible to predict in any detail" and "we don't want providers to know in detail what value the machinery has for us" were two explanations that were given for the limited interest in detailed 
value specifications and virtually nonexistent evaluations of actual created value. Comments like "if there are ergonomic improvements it is always worth it", could also explain some companies' disinterest in more detailed specification and evaluation of actual created value from earlier automation projects.

Instead of using resources to precisely specify desired and evaluate actual created value, attempts to maximize economic value from an investment were often made by 'standardization efforts', i.e, by using resources to standardize routines for commissioning, choice of equipment, installations, operation, upgrading, reconfiguration, programming, maintenance, information handling, documentations, etc, it was assumed that installations of automation systems to create the value 'reduced manual labor time', would translate into lowered production cost for the larger production system over time. Several companies admitted, though, that standardized routines were rarely followed, and new procurement methods were often used for each new automation project, often based on the experience the individual project leader had from earlier investment projects.

The other group of SME:s, about to increase utilization of digital tools were asked the same questions regarding how they specify desired value from increased digital tool utilization. As for the assembly companies, answering the questions was not a straightforward task for the companies. "These questions are more academic than we are used to" and "This is not how we usually work" were typical answers. To a large extent, admitted by two of the interviewed companies, investments in new digital tools were based on gut feelings or a perceived necessity to 'modernize', 'digitalize' and 'learn how to use these IT-tools'. Some comments regarding how they specify desired value were for example:

- “We focus on 'Here and now problem solutions'. New digital tools may help to solve our problems..."

- $\quad$ "The IT projects we have, have currently focused on reducing lead-time by reducing the need for manual working hours. The value for the company has been implicitly assumed with regard to the nature of the project, as it was about automating repetitive and non-creative moments within CAD..."

- "We work with carefully formulated technology specifications and continuous follow-up on projects with external parties. In this way, we are testing and evaluating each new function during the course of the project and reducing the risk of misunderstanding. We thus evaluate the actual functionality of the delivery, rather than the value of the functions".

- "We have no method to further measure the value of IT projects except assuming that automating the CAD process will lead to value."

- "We don't plan for resources that may be needed for adjustments of the final tool installations..."

- "We have very limited resources to specify desired value from digitalization projects, how actually created value should be measured or to what degree the ITdepartment's technology specifications actually will generate value for the Production department. We are also aware that these 'savings' in specification resources generate substantial resource consumption later on, to fix everything that does not work after a digitalization project has been 'finished"'. 
The two interviewed suppliers of digital tools found it significantly easier to provide answers regarding value specification methods, compared to the recipients of the digital tools. Comments regarding how their customers specify desired value were for example:

- "I wish they focused more on value, but the focus is almost only on estimated cost reduction."

- 'Desired values are 'faster processes', 'fewer errors', that could be relatively easy to specify and measure, if customers were more interested in doing that."

- "We have not developed a value-based business model yet but would like to see a performance-based business model, which, however, the customers are not particularly interested in".

The experience from the experienced automation integrator was that large vehicle manufacturers with decades of automation experience have more advanced methods to specify desired value and methods to measure actually created value than SME:s. Notably, though, was that the integrator's view was that manufacturers with long time experience of automation and digitalization still have limited focus on specifying value over time, where e.g. resources required for upgrades and maintenance are included.

In summary, the interviewed SME:s only specify 'capacity' and 'improved ergonomics' as desired value. Reduction of hours was the main desired resource reduction. How created value and resource reduction should be measured was not specified. Value was mainly assumed to just 'be there' if correct technical specifications were assured, and hours reduced, which could explain that 'optimizability' and maximization of $V / R$ for operations was never mentioned as a desired value from digitalization projects.

\subsection{Workshop findings from a mid-sized process industry}

The workshops identified that several important project specifications were in place before digitalization projects started, such as desired project start date, project finish date, project cost, some important technical specifications such as theoretical capacity of specific machinery and tools, ability to make process measurements with a certain precision and ability to control certain process settings. Specifications of what the final production machinery should be able to do was also in place, e.g.: 'palletizing', 'packaging' and 'labeling'. However, 'verified usefulness' from different project steps such as secured useful 'packaging' 'labeling', measurements or control, was only specified to a very limited extent, or not at all. It was found that the absence of specified useful communication was particularly important. This absence meant e.g. that work to ensure useful solutions to access process data, and for control signal transmissions, for example through company firewalls was work left for after the project. Ability to secure 'verified usefulness' and a resulting 'cost effective production' was instead generally assumed to automatically be the final project result if installations of the production equipment with correct existing technical specifications were made.

The workshop findings resulted in a collection of several non-satisfying results from earlier digitalization project, e.g. deficiencies regarding:

- Possibilities for useful communication the installations and other IT-systems within the company

- Process measurements and other data, useful for analysis or automatic control

- Possibilities to add new measurement locations 
- Process settings that could only be manually changed

- Useful, flexible, and verified programmed machinery instructions

- Possibilities for cost effective maintenance and upgrading

It was found that an important reason to this result was that project participants prioritized requirements demanding that they should carry out the work and deliver the [limited] technical specifications, actually described in the project order, within time and budget constraints, and not prioritize a non-specified production value. One interesting finding was that the presumably 'obvious' solution to this problem; to secure more detailed specifications of desired high value before automation project start, was anything but obvious. Neither a common picture of actually desired value, nor a costeffective process to arrive at specified desired value, was easy to find.

Individual job descriptions, project manuals and project instructions described what individuals should work with, how all project steps from project idea to project handover should be handled and who should be responsible. But nowhere was it mentioned that desired value from work or project steps should be specified and validated. One workshop participant also mentioned that "we need to consume the annual budget to make sure that we don't get a reduced budget next year", indicating that the reward system where departments to some degree were rewarded for their ability to consume resources also had an impact on the low priority for value specification and measuring.

Resources required to secure higher productivity of the installations after the automation projects had been 'finished' (i.e., optimization efforts) were not considered 'automation project costs' but rather 'production costs'. Some workshop participants also indicated that requirements of significant 'after project costs', i.e. tuning of the machinery to make it produce anything, actually could be viewed as a positive outcome among those project participants that would be the beneficiaries of these required resources.

Another finding was that discussions about technology specifications such as 'power' or 'speed' of machines where generally regarded as significantly more interesting than discussions about how specification of desired value from machine utilization could guide choices of 'power' and 'speed'. Reasons for this were not clearly spelled out but comments that emerged was that value was not found as 'fun' a topic as e.g. 'power', and concerns that thorough value specification could contribute to insights that some 'fun' and 'good to have' machines might not even be needed.

The study of already carried out projects also showed that projects that only involved limited amounts of programming (mainly physical structures) generally generated more satisfying installations compared to installations involving significant amounts of programming. The study indicated that this result was the static nature of physical constructions. It was easy for all to see and measure if the final result created high value.

\section{Analysis}

Making the reflections in ch.1, we assumed that if the 'company' would gain economically from 'reduced hours' one could assume that some individual workers could see a potential equivalent economic loss as they would have less to do and may even lose their job. This potential conflict was avoided in part by never discussing when the savings from the freed hours would be captured. 
Only a few value terms were specified and priorities between different value terms were never mentioned as an issue, handling potential prioritization disagreements.

Specification of the values 'useful' information and control, and how actual created value should be measured were never mentioned as relevant issues, which handled potential diagreements of how value over time should be created. This could also explain that considerations regarding 'optimizability' and maximization of $V / R$ over time were never mentioned.

All digitalization recipients used 'linear' thinking and an 'investment' business model and all potential value from the investments were assumed to be created with internal resources. Network thinking including multiple value creators was not used, making the issue of whom should create the desired value, of limited or no concern.

The findings from the workshops showed that unprecise value specification led to several unsatisfying project outcomes. The consequences for all studied projects in the workshops were that significant resources were required to be able to effectively utilize the digital installations, to adjust production when e.g. products changed, and to efficiently optimize the production, if optimization were possible at all, after the digitalization projects were "finished'. "Inflexible solutions" was also a reason for many SME:s participating in the interview study. As the SME:s and the process industry responded simililarly to our questions, we found it reasonable to assume that the SME:s unprecise or absent value specifications contributed to their "inflexible solutions" outcomes, as is did for the process industry. The negative consequences for the SME:s, assumed resulting from current value specification practices, are also in line with literature reporting ${ }^{3}$.

Despite the identified, and in the case for SME:s, assumed problems, resulting from unprecise value specifications, this practice was generally uncontroversial, as it was seen as beneficial for several reasons. This e.g. avoids a potentially resource demanding, 'wasteful', challenging or boring activity. It also makes it easier to keep precise information of how equipment and projects will increase value, classified for machinery and digital tool providers.

We interpreted these findings as the general method by which the value specification process handles possible disagreements regarding what is actually 'desired value', was by responding to percieved benefits of spending limited resources for value specification, and either avoid value specification altogether, or avoid specification of how actual value should be measured.

When attempting to increase the success rate of digitalization projects, by improving the value specification process, these findings are relevant to consider.

\section{Conclusions and future research}

When attempting to increase resource efficiency by carrying out digitalization projects, SME:s need to reflect over the difference between short-term resource efficient following of organizational, and project models, and efficient securing of technical

\footnotetext{
3 https://www.information-age.com/projects-continue-fail-alarming-rate-123470803/ [accessed 2019-11-06]
} 
specifications, and between long-term resource effective ability to create customer value [17]. Our findings indicate that absent or imprecise value specifications contribute to digitalization projects creating less long-term value for SME:s than what could be assumed potentially possible. However, our findings also indicate that increasing resources and improving value specification will be a challenge as there are also several perceived benefits of spending few resources on value specification and having imprecise value specifications, including avoidance of possible disagreements of what is 'desired value'. When developing an improved value specification process, to improve project outcome, the perceived benefits of imprecise value specification must hence be considered.

This study addresses the "alarming" failure rate of digitalization projects, and contributes to Servitization and value research by taking the digitalization value recipient perspective, which few Servitization studies currently cover. It suggests that improved value specification methods could have a significant positive impact on digitalization project result for SME:s, and that such methods should be developed. It also suggests that development of such methods must consider several questions that will be investigated in future studies e.g. "what are the characteristics of a value adding, value specification method?"

\section{Acknowledgement}

This study was part of the research projects: 'Automated design of production tools' (ADaPT) and 'Efficient automation for adapted products in Swedish factories' (eFactory) financed by the Swedish Agency for Innovation Systems (Vinnova). And 'Sustainable Textile Barriers' (Texbar) financed by Mistra Innovation. The research was performed in the context of the XPRES environment at Rise IVF AB and Mälardalen University.

\section{References}

[1] E. Brynjolfsson and A. McAfee, The Second Machine Age : Work, Progress, and Prosperity in a Time of Brilliant Technologies, W. W. Norton \& Company, New York, USA, 2014.

[2] J. Rifkin, The End of Work, Penguin, New York, USA, 1995.

[3] J. Rifkin, The Zero Marginal Cost Society: The Internet of Things, the Collaborative Commons, and the Eclipse of Capitalism, Palgrave Macmillan, New York, USA, 2014.

[4] P. Carlborg, D. Kindström andC. Kowalkowski, The evolution of service innovation research: a critical review and synthesis, The Service Industries Journal, vol. 34:5, 2014, pp. 373-398

[5] C. Raddats, C. Kowalkowski, O. Benedettini, J. Burtond and H. Gebauere, Servitization: A contemporary thematic review of four major research Streams, Industrial Marketing Management, Article in press, 2019

[6] J.M. Müller, D. Kiel and K.I. Voigt, What Drives the Implementation of Industry 4.0? The Role of Opportunities and Challenges in the Context of Sustainability. Sustainability, vol 10(1), 2018, pp. 247271

[7] I.C.L.Ng and L.A. Smith, Toward a Better Understanding of the Role of Value in Markets and Marketing, Special Issue -Review of Marketing Research, vol. 9, 2012, pp. 207-243

[8] W.R. Stahel, The Performance Economy, Palgrave Macmillan, Basingstoke, England, 2010.

[9] A. de Geus, as cited in Creating Competitive Advantage with HRM, Lesley Partridge, p. 128, 1999

[10] R.F. Lusch, S.L.Vargo and A. Gustafsson, Fostering a Trans-Disciplinary Perspectives of Service Ecosystems. Journal of Business Research, vol 69 (8), 2016, pp. 2957-2963 
[11] C.T. Lai, P.R. Jackson and W. Jiang, Shifting Paradigm to Service-Dominant Logic via Internet-ofThings with Applications in the Elevators Industry. Journal of Management Analytics , vol 4 (1), 2016 pp. 35-54.

[12] L. Sommer, Industrial Revolution-Industry 4.0: Are German Manufacturing SMEs the First Victims of this Revolution?. Journal of Industrial Engineer-ing and Management, vol 8(5), 2015, pp. 1512-1532

[13] R. Adner, Ecosystem as Structure: an Actionable Construct for Strategy. Journal of Management, vol 43(1),2017, pp. $39-58$

[14] D. Leonard-Barton, Wellsprings of Knowledge. Boston: Harvard Business School Press, 1995

[15] G. Walsham, Interpretive Case Studies in IS Research: Nature and Method. European Journal of Information Systems , 1995, pp . 74-81

[16] A. Granlund, M. Wiktorsson, S. Grahn, N. Friedler, Lean Automation Handbook, Vinnova, Sweden, 2016.

[17] D.S. Sink, and T.C. Tuttle, Planning and Measurement in Your Organization of the Future, IE Press, Norcross, GA, 1989 